\title{
The Effectiveness of Using Self-questioning Strategy on Improving Some Basketball Skills among Seventh Grade Students in Amman, Jordan
}

\author{
Nedal Ahmad Alghafary \\ Department of Physical Education Curricula and Teaching Methods, Al-Balqa Applied University, Jordan
}

Received February 21, 2021; Revised March 18, 2021; Accepted April 25, 2021

\section{Cite This Paper in the following Citation Styles}

(a): [1] Nedal Ahmad Alghafary, "The Effectiveness of Using Self-questioning Strategy on Improving Some Basketball Skills among Seventh Grade Students in Amman, Jordan," International Journal of Human Movement and Sports Sciences, Vol. 9, No. 3, pp. 480 - 487, 2021. DOI: 10.13189/saj.2021.090313.

(b): Nedal Ahmad Alghafary (2021). The Effectiveness of Using Self-questioning Strategy on Improving Some Basketball Skills among Seventh Grade Students in Amman, Jordan. International Journal of Human Movement and Sports Sciences, 9(3), 480 - 487. DOI: 10.13189/saj.2021.090313.

Copyright $\bigcirc 2021$ by authors, all rights reserved. Authors agree that this article remains permanently open access under the terms of the Creative Commons Attribution License 4.0 International License

\begin{abstract}
Aim: The present study aimed at investigating the effectiveness of self-questioning strategy in improving some basketball skills among seventh grade female students in Amman, Jordan. Method: This was a quasi-experimental study. The study was conducted in the period between $6^{\text {th }}$ of January 2019 and $14^{\text {th }}$ of February 2019. The study included a random sample of 36 students from the seventh grade. The participants were randomized equally into a control group $(\mathrm{n}=24$, received traditional teaching) and an experimental group $(\mathrm{n}=24$, instructed through self-questioning strategy). The study used the anthropometric measurements and valid and reliable skills pre and posttests to identify any significant effect of the self-questioning strategy on the shooting, passing and dribbling basketball skills among the study participants. Results: The results of the study showed that there were significant statistical differences at significance level $(\alpha \leq 0.05)$ in the mean scores of the shooting skill $(t=6.0684$, $\mathrm{p}=0.000)$, passing skill $(\mathrm{t}=4.1412, \mathrm{p}=0.000)$ and dribbling skill ( $\mathrm{t}=2.4581, \mathrm{p}=0.0178$ ) between the control group and the experimental group in favor of the experimental group referred to the use of self-questioning strategy. Conclusion: The study concluded that self-questioning strategy is an effective strategy in improving shooting, passing and dribbling basketball skills. The study recommends conducting further research studies to support the research-based evidence regarding the effectiveness of self-questioning strategy on improving the basic sport
\end{abstract}

skills among school students.

Keywords Self-questioning, Basketball, Shooting, Passing, Dribbling, Quasi-Experimental

\section{Introduction}

We live today in a rapidly changing world, with tremendous development in all areas of life in general, and in the field of science and technology in particular [1]. Accordingly, the perception of the educational process has changed, in addition to the fact that the educational process is no longer the product of external factors such as the teacher, the curriculum, and the educational environment only [2], but there are internal factors that affect a great deal in the learning process, such as the learner's ability to understand and think, so attention towards thinking of the learner [3]. The learner has become the driving tool and the focus of the learning process, considering that the learner is the final product in which the educational goals are achieved [4]. Among the criteria by which the quality of the educational process can be judged is the extent to which the learner possesses knowledge, experiences, skills, and positive attitudes inherent in his/her personality of all kinds. [5].

Successful teaching is one that achieves the set goals and 
provides students with information that affects their personality [6], formation and thought, as well as a successful teacher who makes students participate in teaching to increase their benefit and accustom them to facing situations and trying to solve the problems they encounter, also under his/her supervision [7]. Therefore, the successful teacher is the one who selects the appropriate method for the nature of the subject to be explained and taught, and in many cases the traditional method of teaching does not achieve the goal or the desired outcomes, especially in the field of physical education because it combines theoretical and practical teaching of sport skills, and since the learner is the basis of the educational process and is the cornerstone of it, it is necessary to create a kind of interaction between the teacher and the learner and work to stimulate thinking among the learner [8].

Hence, the researcher's tendency was towards using modern strategies in teaching sport skills, including the strategy of asking self-questions, which is based on directing the learner to a set of questions to himself during the processing of information, which makes him more integrated with the information he/she learns and creates awareness of thinking processes to build relationships between the parts of the subject of study and between the student's information, experiences and beliefs on the one hand, and the study topics on the other side $[8,9]$.

The aim of this strategy is to identify the student's previous knowledge about the subject of the lesson and its interest. It also helps the teacher in shaping learning experiences and helps students to reach the scientifically accepted concept [10]. It creates a certain mental trend among students and creates a guide for them to guide them in learning and in data processing [11]. The information helps to organize and remember students' information and generate new ideas, which makes them think about the steps that help them solve the problem from its various aspects. In addition, this strategy activates the metacognitive processes that exist among students, linking previous knowledge with new information, analyzing it in depth and organizing it, which leads to knowledge acquisition and integration [12].

The teacher's role differs in the method of self-questioning from his/her role in the traditional method of education followed [13], and this is evident in the teacher preparing the learning environment, preparing the tools used, and following up on the students 'progress in learning [14]. The teacher also directs the behavior of groups during learning and provides them with help when they need to. It also teaches them the skills of asking questions [15].

The researcher believes that the physical education curriculum is fertile and capable of implementing and applying most modern strategies in the educational process, teaching methods and approaches. Physical skills and sports are full of opportunities, and they help their practitioners in developing their skills, achieving self-realization and performing sports skills with confidence and mastery [16]. Therefore, It is necessary to use this modern strategy (the self-questioning) in teaching basic basketball skills $[17,18]$.

Therefore, the researcher believed that the use of self-questioning education will lead to help in solving some of the difficulties and problems, as it works to benefit from the experiences of some distinguished students in basketball in teaching their colleagues under the supervision of the teacher, and that the variation in the level of students stimulates them to achieve better learning. Based on the previous demonstration, the present study aims at investigating the effectiveness of self-questioning strategy on improving some basketball skills among seventh grade female students at intermediate stage schools in Amman city, Jordan.

\section{Research problem}

Many scientific studies that used modern strategies in teaching the physical education curriculum have confirmed the achievement of the required objectives of the educational process, such as the study of Amin and Younes (19), Rabi (20), Ahmed [21] and the study of Hayek [22]. Where the results of these studies confirmed the positive effects of using some modern strategies in teaching physical education.

Through the researcher's experience in the field of physical education, which depends on many social and human sciences, and depends on theoretical teaching and practical application in teaching mathematical skills, and that the student is able to solve many of the problems and obstacles that he/she faces in performing sport skills. From here the research problem emerged in the study, which aims to identify the effect of the self-questioning strategy on improving basketball skills among seventh-grade students at Al-Qassem Private school affiliated to Wadi Al-Seer Brigade educational directorate, Amman.

\section{Significance of the Study}

- This study is the first local experiment dealing with the effectiveness of the self-inquiry strategy in the field of physical education.

- Provides physical education curriculum designers in the Ministry of Education with results that benefit them during curriculum development.

- This study depends on stimulating thinking among the student in the playing yard and in the field.

- Opening the door for researchers to investigate the impact of self-questioning strategy on other sport skills. 


\section{Purpose of the Study}

The purpose of the present study is to investigate the effectiveness of self-questioning strategy on improving some basketball skills among seventh grade female students at Amman city, Jordan.

\section{Research hypothesis}

$\mathrm{H}_{0}$ : There is no significant statistical difference at $\alpha \leq 0.05$ in the mean scores of basketball skills post-test between the control group (received traditional teaching) and the experimental group (used self-questioning strategy) referred to the educational method.

\section{Research Definitions}

Self-Questioning Strategy: An organized internal dialogue that analyzes the information presented in the readable text by setting a set of questions that express the contents and ideas contained in the educational material Self-Questioning strategy was defined operationally as a set of questions that students of the experimental group ask among themselves before and during learning. These questions aim to stimulate students' thinking processes about the topics that are taught to them during the period of the experiment with the intention of understanding and criticizing or judging them.

Basketball skills: Basketball skills can be broken down into two primary categories: Offensive skills: shooting, rebounding, passing, and dribbling, and Defensive skills: blocking, stealing, and again, rebounding.

\section{Previous Studies}

Despite the large number of studies sought to identify the effectiveness of different educational strategies on improving sport skills, there were no specific studies that sought to investigate the effectiveness of self-questioning strategy on improving basketball skills.

Ameen and Younis [19] conducted a study that aimed to identify the effect of using cooperative learning method on learning some volleyball skills represented (preparation With the hands from the top - the crushing beating - the blocking wall in volleyball (at the Faculty of Education at Al-Azhar University, and the study sample included (60) students, and the researcher used the experimental method by designing two groups, the first is control and the other is experimental, where the experimental group outperformed the control group, and the researcher recommends using an application The method of cooperative learning on volleyball skills and the use of contemporary teaching methods in line with the development of the modern global volleyball game.

Rabi [20] conducted a study that aimed to identify the effect of cooperative learning method on motor performance and cognitive achievement of some basic skills in ballet (Movements of the support and the rotation of the man on the ground), and the researcher used the experimental method by dividing the students into two groups (experimental and control). The most important recommendations were the application of the cooperative learning method on ballet skills, as well as the use of the same method on other games.

Ahmed [21] conducted a study, which sought to identify the effect of using both cooperative learning and learning methods for mastery on learning some football skills. The researcher used the experimental method and the study sample included ( 75 students from the fourth year students from the Department of Sports Education at the College of Education at Al-Azhar University, were divided equally into (3) groups, two experimental groups and the other as a control group. The results revealed the superiority of the two experimental groups over the control group and that learning for mastery is better than cooperative learning.

Al-Hayek [22] conducted a study that aimed to identify the effect of using cooperative learning strategy in teaching basketball on the self-concept in its three dimensions among students of the Faculty of Physical Education and their attitudes towards basketball. To achieve this, the study sample consisting of 49 male and female students (18 male and 31 female students) who were enrolled in the basketball (1) course, sections $1 \& 2$ were selected. The cooperative learning strategy was adopted for eight weeks. In order to test the study hypotheses, a Tennessee Self-Concept Scale was used, and a questionnaire was designed to find out the students' attitudes. The two scales were administered to the students as a measure before conducting the study (Pertest) in the second semester $2002 / 2003$, then they were re-applied after completion. The results of the statistical analysis resulted in the existence of statistically significant differences between the members of the experimental group and the control group on the self-concept scale with its three dimensions (physical, personal, social) and the overall self-concept. The results revealed that there were statistically significant differences between the members of the two groups on the attitudes scale and in three out of four domains, which are the field of subject content and nature, the subject teacher, the teaching method field and on the scale in its overall form, in favor of the experimental group. There are statistically significant differences between members of the two groups on the field of basketball importance. The results also showed that there were no statistically significant differences between members of the two groups referred to gender variable.

\section{Methodology}

Research design: This was a quasi-experimental research study.

Research Population and Sample: The population of 
the study was all seventh grade female students $(\mathrm{N}=93)$ at Al-Qassem private school affiliated to Wadi Al-Seer Brigade educational directorate, Amman. The seventh grade students were distributed over two classes, the first consisted of 48 students, whereas the second class consisted of 45 students. The researcher purposively selected 48 female students to participate in the present study. The participants were randomly blinded into two groups; the control group that consists of 24 subjects and the experimental group that consists of 24 subjects. Randomization was performed using randomization computer software that assigned the participants randomly into either the control or the experimental groups.

\section{Homogeneity of the Study Groups}

The researcher examined the homogeneity of the two study groups through calculating the significance of the differences between the control and the experimental group with regard to their growth rate (age, height, weight), and skills level (Shooting, passing, dribbling) (Table 1). The results shown in table (1) indicated that there were no significant statistical differences between the control group and the experimental group at the baseline.

\section{Data Collection Measures}

The researcher used the following as data collection measures

1. Anthropometric measurements (Age, weight, Height): The participants' age was calculated based on the data retrieved from the school administration based on the academic files of the students. In addition, the participants' weight and height were measured using calibrated and accurate devices.

2. Basic basketball skills' pre and post-tests: After reviewing the related literature and previous studies, the researcher adopted the valid and reliable basketball tests for the shooting, dribbling and passing basketball skills that are appropriate for the age category under investigation. The adopted tests were submitted to a group of experts to ensure the appropriateness of using them to achieve the study objectives. The researcher adopted an agreement standard of $80 \%$ between the experts' opinions about the appropriateness and validity of the tests for the study sample.

A. Passing test: The objective of this test was to test the accuracy of passing skill. Instruments needed were: a legal basketball, timing watch, whistle, and a smooth wall)

Procedure:

- A straight line, parallel to the wall, was drawn on a distance of 2 meters from the wall.

- The students with a basketball stands behind the starting line.

- The student passes the basketball at the chest level towards the wall for 30 seconds.

- The number of passes are recorded

- The scores are calculated based on the number of passing times performed by the students.

B. Dribbling test: The objective of this test is to measure the speed of the dribbling. Instruments needed were: five cone barriers, timing watch, legal basketball, and a whistle).

Procedure:

- The plastic cone barriers were distributed over a 12-meter straight line, with a distance of 2 meters between each two cones.

- The student stands at the start line and begins to perform winding running between the barrier cones while dribbling the ball when the whistle is launched.

- The researcher calculated the score of the student based on the time needed to pass the cone barriers successfully.

C. Shooting test: The objective of the test was to measure the shooting accuracy and scoring. Instruments needed were: (A legal basketball, a legal basketball goal, timing watch, and a whistle). Procedure:

- The student stands at anywhere she chooses under the basketball.

- When launching the whistle, the student shoots towards the basketball goal accurately and quickly to score the highest number of goals within a time frame of 60 seconds (One minute).

- Each student was given two trials. The best trial is adopted so that she scores the highest number of goals achieved in one trial. 
Table 1. Homogeneity results of the study groups

\begin{tabular}{ccccccccc}
\hline \multirow{2}{*}{ Variable } & \multirow{2}{*}{ Measurement Unit } & \multicolumn{2}{c}{ Experimental group } & \multicolumn{2}{c}{ Control Group } & $\mathrm{t}$ & $\mathrm{p}$ \\
& & & $\mathrm{M}$ & $\mathrm{SD}$ & $\mathrm{M}$ & $\mathrm{SD}$ & & \\
\hline \multirow{3}{*}{ Growth rate } & Age & Years & 12.76 & 0.625 & 12.68 & 0.547 & 0.4719 & 0.6392 \\
& Height & $\mathrm{cm}$ & 155.13 & 3.614 & 155.4 & 3.581 & 0.2600 & 0.7960 \\
& Weight & $\mathrm{Kg}$ & 47.08 & 0.715 & 46.89 & 0.706 & 0.9263 & 0.3591 \\
& Shooting & point & 6.514 & 1.647 & 6.521 & 1.973 & 0.0133 & 0.9894 \\
\multirow{3}{*}{ Skills Level } & passing & point & 22.236 & 3.662 & 22.871 & 3.481 & 0.6157 & 0.5411 \\
& dribbling & Seconds & 17.267 & 4.018 & 17.743 & 3.893 & 0.4168 & 0.6788 \\
\hline
\end{tabular}

Table 2. The correlation coefficients between the test and retest scores.

\begin{tabular}{|c|c|c|c|c|c|c|c|}
\hline \multirow{2}{*}{$\#$} & \multirow{2}{*}{ Variable } & \multirow{2}{*}{ Measurement Unit } & \multicolumn{2}{|c|}{ test } & \multicolumn{2}{|c|}{ Retest } & \multirow{2}{*}{$\begin{array}{c}\text { Correlation } \\
\text { coefficient }\end{array}$} \\
\cline { 4 - 7 } & & & $\mathrm{M}$ & $\mathrm{SD}$ & $\mathrm{M}$ & $\mathrm{SD}$ & \\
\hline 1 & Shooting & Point & 6.614 & 1.217 & 6.347 & 1.194 & 0.965 \\
\hline 2 & Passing & Point & 22.306 & 1.246 & 22.211 & 1.207 & 0.972 \\
\hline 3 & Dribbling & Seconds & 17.624 & 1.341 & 17.616 & 1.403 & 0.976 \\
\hline
\end{tabular}

\section{Validity}

To verify the validity of the previous physical tests, differential validity was chosen based on comparing the performance of two groups, one of which is distinct from the other, by administering the tests to a sample of basketball players and allocating basketball from basketball players in different Jordanian clubs and comparing it to another group of students different from the basic sample study.

It has been evident that there are statistically significant differences in favor of the distinguished group from the non-distinguished group in measuring the physical fitness components of basketball, which indicates the validity of the tests in measuring what was set for it 7 days from the first administration.

\section{Reliability}

The reliability coefficient was calculated for the selected tests by administering the test and re-administering it for the skills tests on a sample of second-level students other than the basic study sample. The results shown in table (2) indicate the correlation coefficients between the test and retest.

It is evident from the results shown in table (2) that the correlation coefficients between test and retest were ranging between 0.965 and 0.976 , which revealed that the tests had high reliability degree.

3. Skills tests: With reference to previous studies, the researcher selected three basketball skills to be investigated in the present study. These skills were shooting, passing and dribbling.

4. Self-Questioning Approach: The teacher introduces the skill to students with its educational steps and technical aspects in (10) minutes through verbal explanation + performing a model, then students learn by asking a number of questions related to each skill and then applying the correct answers to each question with skill training. Among each group is a high-level student, two intermediate students, as well as two low-level students and this is recognized through previous skill tests.

In the beginning, students were trained to use the self-inquiry strategy through the following steps:

- Predicting and activating previous knowledge:

The teacher begins by presenting the topic of the lesson to the students and encourages them to raise some questions to activate metacognition processes in order to know their previous experiences on the topic of the lesson.

Each student looks at the subject of the lesson (skill) and then asks himself:

What is the subject of the lesson centered on based on its title? Why do I expect this? Among the useful means in this is the student drawing concepts maps or diagrams because of the information they have on the subject of the lesson (Practicing the skills).

- Prediction evaluation and self-reflection: The student practices the skill and tests to what extent his previous expectations were correct about this skill. If his predictions were correct about this skill, he continues to predict and think. Then asks him/herself: What is the proposed solution to the problem? Or what is the expected end of it?

If the predictions are not identical or close to the subject of the skill, the student should ask himself: Why are my predictions or my expectations incorrect? How can I make different predictions or expectations?

- Final evaluation: the teacher discusses with the students the results he has reached by raising some questions that help him in dealing with, analyzing 
and evaluating information and determining how to use it in other skills.

\section{The Study Intervention}

Pretest measurements

The pretest measurements for the control group and the experimental group were performed in the period between $15 / 03 / 2019$ to $30 / 04 / 2019$.

Interventional Procedure

The main study intervention was performed as two lectures per week (theoretical and practical); each lecture lasted for 45 minutes, for a period of six weeks for both the control and the experimental groups.

The experimental group was instructed using the self-questioning strategy, whereas the control group was instructed traditionally, which depended on the traditional instruction and direct feedback for the learners.

\section{Posttest measurements}

After completing the interventional procedure, the researcher performed the posttest measurements for the control and the experimental group using the same skills tests used in the pre-measurements.

\section{Data processing and Statistical Analysis}

After completing the pre and post measurements, the researcher collected the data, organized and coded them in order to analyze the results. The Statistical Package of Social Sciences (SPSS) (V. 26, IBM Corporation) was used in data analysis. Descriptive statistics such as means and standard deviation, in addition to two independent samples t-test were used in processing the participants' data in this study. A significance level of $(\alpha \leq 0.05)$ and a confidence interval of $(95 \%)$ were used in the data analysis.

\section{Results}

The present study sought to investigate the effectiveness of self-questioning strategy on improving some basketball skills among seventh grade female students at Al-Qassem private school affiliated to Wadi Al-Seer Brigade educational directorate, Amman. The results shown in table (3) represent the pre-test scores for the control group and the experimental group. The results showed that there was no significant statistical differences at $\alpha \leq 0.05$ between the mean scores of shooting, passing or dribbling skills between the control group and the experimental group.

The results shown in table (4) represent the two independent samples t-test results to investigate the significant differences in the post-test mean scores. The results indicated that there were significant statistical differences in the mean scores of the posttest of the shooting skill $(\mathrm{t}=6.0684, \mathrm{p}=0.0001)$, passing skill $(\mathrm{t}=$ 4.1412, $\mathrm{p}=0.0001)$ and dribbling skill $(\mathrm{t}=2.4581, \mathrm{p}=0.0178)$ between the control group and the experimental group in favor of the experimental group that got higher mean scores, which revealed an effect of the interventional procedure represented by the self-questioning strategy.

Table 3. Mean and standard deviations for the basketball skills pretest for the control group and the experimental group

\begin{tabular}{|c|c|c|c|c|c|c|}
\hline Skill & \multicolumn{2}{|c|}{ Control group } & \multicolumn{2}{c|}{$\begin{array}{c}\text { Experimental } \\
\text { group }\end{array}$} & $\mathrm{t}$ & $\mathrm{Sig}$ \\
\hline & $\mathrm{M}$ & $\mathrm{SD}$ & $\mathrm{M}$ & $\mathrm{SD}$ & & \\
\hline Shooting & 6.29 & 1.05 & 6.45 & 1.23 & 0.4847 & 0.6302 \\
\hline Passing & 22.03 & 2.17 & 22.21 & 1.98 & 0.3002 & 0.7654 \\
\hline Dribbling & 17.02 & 3.32 & 16.69 & 3.11 & 0.3554 & 0.7239 \\
\hline
\end{tabular}

Table 4. Mean and standard deviations for the basketball skills posttest for the control group and the experimental group

\begin{tabular}{|c|c|c|c|c|c|c|}
\hline Skill & \multicolumn{2}{|c|}{ Control group } & \multicolumn{2}{c|}{$\begin{array}{c}\text { Experimental } \\
\text { group }\end{array}$} & $\mathrm{t}$ & $\mathrm{Sig}$ \\
\hline & $\mathrm{M}$ & $\mathrm{SD}$ & $\mathrm{M}$ & $\mathrm{SD}$ & & \\
\hline Shooting & 6.33 & 1.12 & 8.58 & 1.43 & 6.0684 & 0.0001 \\
\hline Passing & 22.36 & 2.23 & 24.71 & 1.66 & 4.1412 & 0.0001 \\
\hline Dribbling & 17.67 & 3.11 & 19.79 & 2.86 & 2.4581 & 0.0178 \\
\hline
\end{tabular}

Based on the previous results, we reject the null hypothesis and accept the alternative hypothesis stating that "There is significant statistical difference at $\alpha \leq 0.05$ in the mean scores of basketball skills post-test between the control group (received traditional teaching) and the experimental group (used self-questioning strategy) referred to the educational method"

\section{Discussion}

The present study investigated the effectiveness of self-questioning strategy on improving some basketball skills among seventh grade female students at Al-Qassem private school affiliated to Wadi Al-Seer Brigade educational directorate, Amman. The results showed that there were significant statistical differences in the mean scores of the skills posttest in favor of the experimental group, which revealed a significant improvement in the aforementioned skills among the female students in the experimental group. These results were referred to the use of self-questioning strategy, which helped students in the experimental group to think more accurately, carefully and in a regular manner, improve the level of the shooting, dribbling and passing skills, listen to themselves as they think as they become more aware of their strengths and weaknesses, and increased students' control over themselves as learners and enabled them to improve their skillful performance $[8,11]$.

The self-questioning strategy enables the learner to achieve significant progress in the learning structure, and for the learner to plan, monitor, control and evaluate his own learning, and thus it improves the learners 'acquisition of different learning processes and allows them to assume 
responsibility and control in the cognitive processes associated with learning $[11,14]$.

The self-questioning strategy is distinguished by the fact that it helps students formulate their questions about the topic, makes them able to dialogue and present what they know and what they do not know, and helps them rely on themselves in building meaning through their discovery of it, and thus its impact remains long, and increases their understanding of the topic and unleashes their energies towards Teamwork [10]. Thus, they become more efficient learners, and it helps them to transmit the impact of learning, increases their motivation to learn and thus leads to meaningful learning, and encourages them to think in a variety of ways and with different levels of complexity, use information and employ it in different science situations, and achieve better learning by increasing the learner's ability to think in a better way, It makes them more sensitive to the important parts of the lesson content and to monitor their understanding of the educational material, that is, to become aware of what they did not understand [14].

Despite the promising effectiveness of the self-questioning strategy on improving the basketball skills, still there is a significant lack of studies examining its effectiveness, which affects the strength of the research-based evidence about its effectiveness. Therefore, there were no previous studies to serve as a baseline in comparing the results of the present study.

In conclusion, the present study concluded that the self-questioning strategy is an effective approach to improving the basketball skills among seventh grade female students. However, the present study recommends conducting further research to ensure its effectiveness, and recommends taking into consideration the integration of self-questioning strategy when developing or designing the physical education curricula for elementary stage grades in Jordanian ministry of education.

\section{Conflict of Interest}

No conflict of Interest

\section{Source of Funding}

This research is not funded.

\section{REFERENCES}

[1] Hùng, Phạm Phi; Vinh, Nguyen Quang, "The role of information technolnov for nhvsical education at $\mathrm{Ba}$ Ria-vung Tau college of education in era 4.0”. 2020.

[2] Pratama, Henri Gunawan, "Profile of Physical Fitness Level of Students-High School Students in Trenggalek Regency Based on TKJI. ACTIVE," Journal of Physical Education, Snort, Health and Recreation, Vol 7, no. 3, pp. 142-145, 2018.

[3] Lawrence, Japhet E.; Tar, Usman A, "Factors that influence teachers' adoption and integration of ICT in teachino/learnino nrocess " Fdurational Media International, Vol 55, No. 1, pp. 79-105, 2018.

[4] Hyun, Jung; Ediger, Ruth; Lee, Donghun, "Students' Satisfaction on Their Learning Process in Active Learning and Traditional Classrooms," International Journal of Tonchino and Ionrning in Higher Education, Vol 29, No. 1, pp. 108-118, 2017.

[5] Salloum, Said A., et al. "Factors affecting the E-learning acceptance: A case study from UAE," Education and Information Technologies, Vol 24, No. 1, pp. 509-530, 2019.

[6] 7ierer Klauc. Wisniewski Renedikt "I/sino student feedback for successful teaching”. Routledge, 2018.

[7] Kebritchi, Mansureh; Lipschuetz, Angie; Santiague, Lilia. "Issues and challenges for teaching successful online courses in higher education: A literature review". Journal of F.durational Technology Systems, Vol 46, No. 1, pp 4-29, 2017.

[8] Dawood, Ahmed. "Fundamentals of theoretical and practical teaching," Jaffa Scientific Publishing and Distribution House, Amman, Jordan, 2014.

[9] Al-Swelmyeen, Monther Bsharh, et al. "The Effect of Self-Questioning Strategy in Developing Independent Thinkino in Teachino Phvsics" Cinriot Journal of Educational Sciences, Vol 15, No. 3, 2020.

[10] Alutaybi, Maraam; Alsowat, Hamad. "The Effectiveness of Isino Self-Ouestionino Strateov in Developing Strategic Listening and Self-Regulation," 2020.

[11] Thohir, Lalu. "The Explicit Comprehension-Strategy Instruction: Question-Answer Relationship VS Self-Questio nino" In - IINNES International Conference on ELTLT. Pp. 205-310, 2017.

[12] Qahtani, Huda A.; AL Gaseem, Mohammed M. "The Effectiveness of Teaching Science Using Self-Questioning Strateov" Inurnal of Fdurational and Psychological Studies, Vol 13, No. 1, pp. 151-174, 2019.

[13] Liu, J.; Xu, C.; Hui, P. M. "Evolutionary games with celf-nuestionino adantive mechanicm and the Ising model," EPL (Europhysics Letters), Vol 119, No. 6, 2017.

[14] Al-Shwaili, Haider Muhson Salman. "The impact of the Roundtable and Self-Questioning strategies on achievement and self-efficacy For students of the Faculty of Education in the suhiect of research curricula "Inurnal of Fdurational and Psychological Researches, Vol 18, No. 68, 2021.

[15] Moreno-Guerrero, Antonio-José, et al. “Augmented reality as a resource for improving learning in the physical education classroom," International Journal of F.nvironmental Research and Public Health, Vol 17, No. 10, 2020.

[16] D'elia Francesea "The training of physical education teacher in primary school," 2019 
[17] Carse, Nicola; Jess, Mike; Keay, Jeanne. "Primary physical education: Shifting perspectives to move forwards," Furnnean Phvsical Education Review, Vol 24, No. 4, pp. 487-502, 2018.

[18] Yarmak, Olena, et al. "The use of modern means of health imnrovino fitness during the process of physical education of student youth," 2017.

[19] Ameen, Y; Younis, S. "The effect of using the cooperative learning method on the level of skill performance of some volleyball skills for students of the Physical Education Department at Al-Azhar University," The Scientific Journal of Physical Education Sciences, pp. 637-654, 2017.
[20]Rabi', M. "The effect of using the cooperative learning method on the motor performance and cognitive achievement of some basic skills in ballet for students of the teaching division of the Faculty of Physical Education in Tanta," Journal of educational sciences. Vol 12, No. 2, pp. 127-142, 2019.

[21] Ahmad, I. "The effect of some teaching methods on learning some football skills". Unpublished PhD Thesis, Faculty of Physical Education, 2015.

[22] Al-Hayek, S. "The Effects of Using Cooperative Learning Strategy in Teaching Basketball on Physical Education Students' Self - Concept and Attitudes," Dirasat: Educational sciences, Volume 1, pp. 174-184, 2010. 